chromosome 10p and monosomy 15q26.3- > qter which contains the region coding for IGF1R. IGF-1 $(243 \mu \mathrm{g} / \mathrm{L})$ and IGFBP-3 (3501 ng/ml) levels were markedly elevated; +4.7 SDS and +3.3 SDS respectively. The marked elevation in IGF-1 levels was considered a relative contraindication to $\mathrm{GH}$ therapy.

Discussion Haploinsufficency of IGF1R gene is associated with elevated levels of IGF-1 as a result of target organ resistance. Exogenous growth hormone, while further elevating IGF-1, in many cases facilitates catch-up growth albeit to a lesser extent than other ex-SGA infants. In this case IGF-1 levels were exceptionally high, precluding growth hormone therapy.

Conclusion Deletions involving the IGF1R gene are a rare but treatable cause of short stature. This case is unusual however, as marked elevation of IGF-1 at baseline precluded GH therapy.

\section{PO-0070 PECULIARITIES OF THE GROWTH HORMONE AND INSULIN-LIKE GROWTH FACTOR (IGF-1, IGFBP-3) SECRETION IN GENETICALLY DETERMINED TYPES OF SHORT STATURE IN UZBEKISTAN}

NSH Ibraghimova, MD Mirkhaydarova. Laboratory of Genomics, Institute of Bioorganic Chemistry Academy of Sciences Republic of Uzbekistan, Tashkent, Uzbekistan

\subsection{6/archdischild-2014-307384.741}

Goal To study the growth hormone $(\mathrm{GH})$ and insulin-like growth factor (IGF-1, IGFBP-3) secretion in genetically determined types of short stature (GDSS) in Uzbekistan.

Materials and methods We examined 92 patients with GDSS [11 - Russel-Silver syndrome (RSS), 16 - Noonan syndrome (NS), 10 - Sekkel syndrome (SS), 9 - Prader-Willi syndrome (PWS), 8 - Cornelius de Lange syndrome (CLS), 38 girls with TS] at the age of 7-18. A level of GH, IGF-1, IGFBP-3, anthropometry (SDS) was studied.

Results Stunting of various degrees of expression was observed in all patients with GDSS but it was most expressed in patients with RSS $(-5.16 \pm 1.18$ SDS), SS $(-4.18 \pm 1.12$ SDS) and CLS $(-6.10 \pm 1.14$ SDS $)$. A reliably low level of GH vs. the control was found in patients with CLS $(0.64 \pm 0.05 \mathrm{ng} / \mathrm{ml}, \mathrm{p}<0.05)$, RSS $(0.7 \pm 0.04 \mathrm{ng} / \mathrm{ml}, \mathrm{p}<0.05)$, SS $(1.02 \pm 0.07 \mathrm{ng} / \mathrm{ml}, \mathrm{p}<$ 0.05 ) on the background of a low level of IGF-1 and IGFBP-3. Patients with NS, TS and PWS had a level of GH within the lower limit norm, 12 girls with TS had a GH level which was reliably low $(0.04 \pm 0.05 \mathrm{ng} / \mathrm{ml}, \mathrm{p}<0.05)$ but IGF-1 and IGFBP-3 rates corresponded to the lower limit of the age norm. Conclusions In Uzbek patients with GDSS pronounced stunting was found in patients with RSS, SS and CLS which was associated with disturbances of a direct and reverse relation in the GH-IGF-IGFBP-3 system. A low GH level and relative deficiency of IGF-1 and IGFBP-3 in girls with TS was related with disturbances in the pituitary-ovarian system.

\section{PO-0071 ROLE OF GROWTH HORMONE THERAPY IN CLINICAL, LABORATORY, RADIOLOGICAL IMPROVEMENT OF CHILDREN WITH VITAMIN-D DEPENDENT RICKETS TYPE-2}

'S Elmi, ${ }^{2}$ REZA Erfani Sayyar, ${ }^{3}$ SAM Elmi. 'Pediatric Department, Mashad University of Medical Science, Mashhad, Iran; ${ }^{2}$ Intensive Care Unit Department, Mashad University of Medical Science, Mashhad, Iran; ${ }^{3}$ Health Care Department, Mashad University of Medical Science, Mashhad, Iran

10.1136/archdischild-2014-307384.742
Rickets is a disease in on growing bones due to precipitate disorders of calcium $(\mathrm{Ca})$ and phosphor $(\mathrm{P})$ in matrix of growth plate before epiphysial closing. Different types for rashitism including nutritional, hypophosphatemic and vitamin-D dependent rickets) VDDR). VDDR is a result of severe vitamin D deficiency that had tow subtype:

A) type -1(VDDR-1) because of defect of 1-alfa-hydroxilase enzyme.

B) type -2(VDDR-2) because of mutation in intracellular vitamin-D receptor (VDR) associated with some especial symptoms like alopesia (global head hair loss) and short stature. this disease needs to high dose of vitamin-D analogues also calcium complement. although response to treatment is variable.

Cases Introduction We introduce 3 cases of VDDR-2 in a family (2 sisters aged $1.5,5$ years and their 5 years old cousin) who referred to endocrine and metabolic centre in Emam-Reza hospital in Mashhad presenting limb deformities, wide wrist, seizure, disorder in dental growth, alopesia, several bone fractures. they had not been recovered despite receiving sufficient treatment. it was notable when they received growth hormone therapy because of growth failure, their rickets improved dramatically by clinical, laboratory, radiological.

Discussion According to discover several clinical indication for growth hormone therapy during last 50 years, still there are not enough studies about growth hormone therapy in VDDR. As second type of vitamin-D dependent rickets sometimes needs to long time calcium infusion or high dosage of active vitamin-D analogues, so it seems that growth hormone therapy in these patients especially with short stature may improve linear growth and rickets symptoms too.

\section{PO-0072 A BOY WITH DECELERATED LINEAR GROWTH WITH NORMAL GROWTH HORMONE (GH) - INSULIN-LIKE GROWTH FACTOR-I (IGF-I) AXIS HAD AN EXCEPTIONAL RESPONSE TO GH THERAPY}

A Soliman, F Alyafei, AML Sabt, A Adel. Pediatrics, Hamad Medical Centre, Doha, Qatar

\subsection{6/archdischild-2014-307384.743}

$\mathrm{Y} \mathrm{M}$ is a boy who presented at the age of 5.5 years with slow growth He had a birth weight $=3.1 \mathrm{~kg}$ and length $=49.5 \mathrm{~cm}$. Infantile and early neonatal periods are uneventful. He had normal development and appropriate nutritional history. No family history of endocrinopathy and/ or short stature was reported. His measurements were: weight $=16.9 \mathrm{~kg}$, Height $=104 \mathrm{~cm}$ $(\mathrm{HtSDS}=-1.8)$, growth velocity $(\mathrm{GV}=1 \mathrm{~cm} / \mathrm{y})$ and $\mathrm{BMI}=16$ and mid-parental height (MPHt) SDS $=-0.6$. He had no

Abstract P0-0072 Table 1 Growth data of the patient before and after GH therapy

\begin{tabular}{|llllll|}
\hline $\begin{array}{l}\text { Age } \\
\text { year }\end{array}$ & BMI & HSDS & $\begin{array}{l}\text { IGFl } \\
\text { ng/ml }\end{array}$ & $\begin{array}{l}\text { Bone age } \\
\text { years }\end{array}$ & $\begin{array}{l}\text { Notes } \\
\text { Tamner stage }\end{array}$ \\
\hline $\mathbf{4 . 4 8}$ & 16 & -0.4 & 65 & ND & \\
$\mathbf{5 5}$ & 16 & -1.84 & 70 & 3 & Started GH \\
$\mathbf{5 . 7}$ & 16 & -0.7 & 92 & & \\
$\mathbf{6 . 4}$ & 16 & -0.35 & 148 & 4 & \\
$\mathbf{7}$ & 15 & -0.28 & 279 & & \\
$\mathbf{8}$ & 17 & 0.15 & 295 & & \\
$\mathbf{9}$ & 18 & 0.5 & 195 & 8.5 & Tamer 1 \\
$\mathbf{1 0}$ & 20 & 0.5 & 325 & & Tamer 2 \\
$\mathbf{1 1}$ & 22 & 0.5 & 447 & & Tamner 3 \\
\hline $\mathbf{1 2}$ & 22 & 0.83 & 514 & 12.5 & \\
\hline
\end{tabular}


dysmorphic features, skeletal anomalies, goitre or pigmentation. The rest of the examination was unrevealing.

Investigations showed normal CBC, ESR, and liver and renal and thyroid functions. Sweat chloride test, and tissue trans-glutaminase concentrations were normal. His IGF-I level $=70$ (IGF-I SDS $=-1$ ) and his bone age $=3$ years. The peak GH response to clonidine stimulation test $=10 \mathrm{ng} / \mathrm{dl}$. Brain MRI showed normal pituitary gland.

Because of the decelerated growth and marginally low IGF-I a trial of GH therapy was started $(0.035 \mathrm{mg} / \mathrm{kg} /$ day s.c. HS). A rapid catch-up of growth occured during the first 3 years of treatment that was maintained at a slower pace during the following 5 years. Testicular enlargement started at 11 years and at 12 years his HtSDS $=0.8$ and bone age $=12.5$ years. His predicted adult height $=181 \mathrm{~cm}$.

Conclusion Prolonged GH treatment of this boy (normal GH-IGF-I axis) with GH unexpectedly resulted in a HTSDS which surpassed his MPHtSDS by $1.4 \mathrm{SD}$.

\section{PO-0073 WITHDRAWN}

\section{PO-0074 PSEUDO-BARTTER'S SYNDROM AS A FIRST MANIFESTATION OF CYSTIC FIBROSIS IN INFANCY}

S Fustik, T Jakovska, L Spirevska. Center for Cystic Fibrosis, University Children's Hospital, Skopje, Macedonia

10.1136/archdischild-2014-307384.744

Background and aims Metabolic alkalosis in association with low serum electrolyte concentration (hyponatremia, hypochloremia, and hypokalemia) is known complication of cystic fibrosis $(\mathrm{CF})$ in infancy. The condition is a metabolic mimickery of Bartter's syndrome, therefore is sometimes referred to as pseudoBartter's syndrome in CF. The aims of study were to estimate the prevalence of this metabolic disorder as a first manifestation of $\mathrm{CF}$ and the influence of some clinical and genetic factors on its developing.

Methods The records of all 85 newly diagnosed infants with CF in the period from 1998 to 2013 were reviewed. In addition to data of acid-base and electrolyte status at first admission, clinical and CFTR genotype data of patients with pseudo-Bartter's syndrome were analysed.

Results 16 infants had manifestations of hyponatremic/hypochloremic dehydration with metabolic alkalosis, therefore the prevalence of pseudo-Bartter's syndrome among newly diagnosed infants with CF in our region was $18.8 \%$. Mean age of patients was 3.5 (range 1-8) months. Most of them were breastfed. Mean values of blood $\mathrm{pH}$, serum bicarbonate, sodium, chloride and potassium $(\mathrm{mmol} / \mathrm{L})$ were: $7.57 \pm 0.06,44.89 \pm$ $7.23,117.87 \pm 5.38,67.06 \pm 8.48,2.69 \pm 0.47$, respectively. Concerning CFTR genotypes of these patients, a great variability was found: F508del/ F508del (7), F508del/G542X (3), F508del/ $621+\mathrm{G}>\mathrm{T}(1), \mathrm{F} 508 \mathrm{del} / 457 \mathrm{TAT}>\mathrm{G}(1), \mathrm{F} 508 \mathrm{del} / 711+3 \mathrm{~A}>\mathrm{G}$ (1), G126D/V456F(1) and F508del/Unknown (2). Three of them were pancreatic sufficient.

Conclusions The possibility of CF should be seriously considered in any infant with metabolic alkalosis and hypoelectrolytemia, whether or not there are associated pulmonary and/or gastrointestinal symptoms. The initial diagnosis of Bartter's syndrome can be excluded by hypochloruria.

\section{P0-0075 HEAD CIRCUMFERENCE IN THE FIRST YEAR AFTER BIRTH - THE EFFECT OF PRENATAL EXPOSURE TO ORGANOCHLORINES AND PHTHALATES}

${ }^{1} \mathrm{M}$ de Cock, ${ }^{2} \mathrm{MR}$ de Boer, ${ }^{3} \mathrm{M}$ Lamoree, ${ }^{3} \mathrm{~J}$ Legler, ${ }^{1} \mathrm{M}$ van de Bor. ${ }^{1}$ Health and Life Sciences, VU University, Amsterdam, Netherlands; ${ }^{2}$ Health Sciences, VU University, Amsterdam, Netherlands; ${ }^{3}$ Institute for Environmental Studies, VU University, Amsterdam, Netherlands

\subsection{6/archdischild-2014-307384.745}

Background Children with autism may experience increased head growth during the first year of life. Furthermore, early life exposure to endocrine disrupting chemicals (EDCs) may be associated with an increased risk of autism. Exposure to EDCs has been associated with fetal head circumference (HC), however research on long-term effects is scarce.

Objective To assess the association between prenatal exposure to various EDCs and HC in the first year of life.

Methods Cord plasma or breast milk was used to determine exposure to amongst others dichlorodiphenyldichloroethylene (DDE), mono (2-ethyl-5-hydroxyhexyl)phthalate (MEHHP), and mono (2-ethyl-5-carboxypentyl)phthalate (MECPP). Data on HC until 11 months after birth was obtained. Mixed models were composed for each compound. Exposure quartiles, time, and gender were added to the models as fixed effects. Subject was added as a random effect.

Results Boys with high MECPP exposure had a consistently higher HC than lower exposed boys ( $p=0.047)$. This was also observed for girls in Q2 for both MEHHP ( $p=0.018$ ) and DDE $(p<0.001)$ exposure. For MEHHP the difference with the quartile showing the smallest $\mathrm{HC}$ was $2 \mathrm{~cm}$ at 11 months of age, which was not statistically significant (HC Q2: 44.9, 95\% CI 43.2-46.7; HC Q3: 42.9, 95\% CI 42.2-43.5).

Conclusion For MECPP, MEHHP, and DDE exposure over time, a higher $\mathrm{HC}$ was observed in low exposed children in a gender-specific way. Follow-up is warranted to see if associations persist into later childhood and are related to autism spectrum disorders.

\section{PO-0076 PREVALENCE OF OVERWEIGHT AND OBESITY AMONG 5-6-YEAR-OLD CHILDREN IN NORTH PART OF SERBIA}

S Turudic. Department of Pediatrics, Local Health Center "Dr Milorad Mika Pavlovic", Indjija, Serbia

\subsection{6/archdischild-2014-307384.746}

Background and aims Overweight and obesity among children became an important public health concern as their prevalence within the preschool population has been markedly increased in last decades. The aim of the present study was to examine and compare the prevalence of overweight and obesity among 5-6 year old children either sex in year 2003 and year 2013.

Methods Overweight and obesity were measured by body mass index (BMI). BMI 85-95th percentile was considered as overweight and BMI $\geq 95$ th percentile represents obesity. The study was performed in the total population of 859 nonselected 5-6 year old children (423 in 2003 and 436 in 2013) by retrospective analysis of their medical documentations.

Results The overall prevalence of overweight in 2003 was $9.63 \%$, whereas the prevalence of obesity was $9.46 \%$. However, 10 years later, in 2013, the prevalence of overweight was significantly higher $(15.6 \%)$ as well as the prevalence of obesity $(13.53 \%)$. Prevalence of overweight and obesity among 